\title{
PROTOTIPE APLIKASI MOBILE ANDROID YOURDREAMJS UNTUK PELAMAR DAN PENCARI KERJA
}

\section{Prototype Android Mobile Application YourDreamJS for Job Seekers}

\author{
Angela $^{1)}$ dan Honni $^{2)}$ \\ ${ }^{1}$ Sistem Informasi/Fakultas Teknologi dan Desain, Bunda Mulia University \\ ${ }^{1)}$ Sistem Informasi/Fakultas Teknologi dan Desain, Bunda Mulia University
}

Diterima 22 December 2017 / Disetujui 31 January 2018

\begin{abstract}
Work is an activity that is done daily by citizens to meet the needs of life. The high unemployment rate in Indonesia illustrates the difficulties of citizens in getting jobs. The perceived difficulty is when looking for job vacancy information in accordance with the expertise that is owned, because it needs to be made a prototype application that can help citizens in finding job vacancies anywhere and anytime quickly and easily. The method that will be used in making this prototype application, which is data collection which includes literature study and questionnaire, analysis and design done with objectoriented approach using UML diagram and ERD, and development of waterfall rule. Prototype applications to be created using HTML, AngularJS and PHP programming languages. The database used is MySQL. The result is a prototype android mobile application called YourDreamJS. This prototype application can be used by all citizens, especially applicants and job seekers to get job vacancy information based on keywords, type of company and also work location quickly and easily.

Keywords: YourDreamJS, protoype android mobile apps, applicants and job seekers.
\end{abstract}

\begin{abstract}
ABSTRAK
Bekerja merupakan aktivitas yang dilakukan sehari-hari oleh warga untuk memenuhi kebutuhan hidup. Tingginya tingkat pengangguran di Indonesia menggambarkan adanya kesulitan warga dalam mendapatkan pekerjaan. Kesulitan yang dirasakan adalah ketika mencari informasi lowongan kerja yang sesuai dengan keahlian yang dimiliki, karena itu perlu dibuat sebuah prototipe aplikasi yang dapat membantu warga dalam mencari lowongan kerja dimana saja dan kapan saja secara cepat dan mudah. Metode yang akan digunakan dalam pembuatan prototipe aplikasi ini, yaitu pengumpulan data yang meliputi studi pustaka dan kuesioner, analisis dan perancangan dilakukan dengan pendekatan berorientasi obyek menggunakan diagram UML serta ERD, serta pengembangan kaidah waterfall. Prototipe aplikasi yang akan dibuat menggunakan bahasa pemrograman HTML, AngularJS dan PHP. Basis data yang digunakan adalah MySQL. Hasil yang dicapai adalah sebuah prototipe aplikasi mobile android bernama YourDreamJS. Prototipe aplikasi ini dapat digunakan oleh semua warga, khususnya pelamar dan pencari kerja untuk mendapatkan informasi lowongan kerja berdasarkan kata kunci, jenis perusahaan dan juga lokasi kerja secara cepat dan mudah.
\end{abstract}

Kata Kunci: YourDreamJS, prototipe aplikasi mobile android, pelamar dan pencari kerja. 


\section{PENDAHULUAN}

Warga memiliki beragam kebutuhan yang harus dipenuhi untuk menunjang kehidupan. Untuk dapat memenuhi kebutuhan tersebut, maka warga harus memiliki penghasilan yang didapatkan dari bekerja. Untuk mendapatkan pekerjaan, warga dapat mencari informasi mengenai lowongan kerja melalui berbagai media, seperti surat kabar, portal lowongan kerja atau media lainnya.

Dari situs Badan Pusat Statistik, dijelaskan bahwa tingkat pengangguran di Indonesia pada bulan Februari tahun 2016 sudah mencapai lebih dari 7 juta penduduk. Kesulitan warga dalam mencari informasi pekerjaan dan mendapatkan pekerjaan yang cocok dengan keahlian yang dimiliki dapat menjadi faktor penyebab pengangguran.

Dari survei dengan responden sebagian besar pelajar yang belum memiliki pekerjaan untuk mengetahui minat responden terhadap aplikasi pencarian lowongan kerja yang baru diperoleh respon sebanyak $77,4 \%$ merasa tertarik. Sebanyak $80,6 \%$ responden menginginkan aplikasi pencarian lowongan kerja yang dapat mencari informasi lowongan pekerjaan sesuai dengan kata kunci secara lengkap dan cepat. Tampilan aplikasi yang tidak rumit dan mudah digunakan juga menjadi pilihan kedua responden dalam menggunakan aplikasi pencarian lowongan kerja.

Dibuatlah aplikasi yang dapat membantu warga dalam mencari lowongan pekerjaan secara cepat, lengkap dan akurat sesuai dengan keahlian untuk menurunkan jumlah pengangguran yang ada. Tampilan aplikasi juga akan dibuat agar menarik dan mudah digunakan oleh semua kalangan warga.

Berdasarkan latar belakang yang telah diuraikan di atas, maka dapat dirumuskan cara membuat aplikasi yang menarik untuk mencari informasi lowongan kerja secara cepat dan lengkap serta mudah untuk melamar lowongan kerja yang disediakan. $\begin{array}{llr}\text { Akan dibuat hybrid application } \\ \text { dengan mengkombinasikan } & \text { HTML, } \\ \text { JavaScript, CSS, AngularJS dan }\end{array}$ AndroidSDK. Untuk sisi penyediaan data menggunakan REST Web Service dengan bahasa pemrograman PHP dengan database MySQL. Aplikasi ini dibuat untuk smartphone dengan OS Android.

Batasan masalah pada penulisan artikel ini adalah: dapat mengelola menu profile, namun untuk melakukan upload file, seperti Curriculum Vitae, tidak dapat dilakukan melalui aplikasi ini. Untuk melamar kerja, aplikasi ini akan menyimpan data lowongan kerja yang dilamar, namun tidak dapat mengirimkan surat lamaran kepada perusahaan terkait dikarenakan belum ada perusahaan real dari pihak YourDreamJS yang dapat menampung data CV. Prototipe aplikasi ini hanya dibuat untuk digunakan oleh pencari kerja.

Tujuan dari penulisan artikel ini adalah memudahkan warga pencari kerja dalam mendapatkan informasi lowongan kerja dengan menghasilkan aplikasi mobile yang dapat digunakan secara mudah dan menyediakan informasi dengan lengkap dan cepat yang dapat diakses setiap saat.

Manfaat yang akan diperoleh apabila aplikasi pencarian lowongan kerja ini sudah tercapai adalah pencari kerja dapat mencari informasi lowongan kerja dan melamar pekerjaan menggunakan aplikasi ini melalui smartphone. Hal ini dapat menghemat waktu serta meningkatkan kesempatan untuk melamar pekerjaan secara langsung dan mudah.

\section{STUDI PUSTAKA}

\section{Studi Sebelumnya}

Studi yang pernah dilakukan oleh Wahyudi dan Rachmadi (2015) dengan judul Sistem Informasi Lowongan Pekerjaan Berbasis Android, menggunakan bahasa pemrograman Java dan basis data MySQL. Metodologi pengembangan sistem yang digunakan sama dengan yang digunakan dalam artikel ini, yaitu metodologi Waterfall. Kesimpulan dalam 
penelitian ini adalah pengguna dapat berinteraksi dengan pemasang lowongan dan lowongan kerja dapat dilihat di aplikasi bergerak.

Studi yang dilakukan oleh Bogle dan Sankaranarayanan (2012) dengan judul Job Search System In Android Environtment Application of Intelligent Agents mengembangkan sistem cerdas yang mengantisipasi kebutuhan pengguna dan membuat keputusan cerdas berdasarkan aturan preferensi fuzzy dan lokasi, gaji, dan pilihan tunjangan yang bermanfaat bagi pengguna. Hal ini terbukti dalam hasil yang disajikan. Sistem ini dapat diperluas untuk mencakup proses aplikasi yang aman di mana pengalaman dan pendidikan pelamar diverifikasi dengan menggunakan data biometrik bersama dengan rincian aplikasi pekerjaan yang telah diterbitkan di tempat lain. Selain itu proses pencarian kerja bisa meningkatkan perhitungan utilitas dengan memasukkan faktor risiko keberhasilan dalam memilih satu pekerjaan di atas yang lain. Hal ini bisa meningkatkan kemungkinan melamar pekerjaan yang akan paling cocok untuk pemohon pada berbagai tingkatan.

Kontribusi yang diberikan dalam tulisan ini yaitu mengkombinasikan hasil dari dua studi sebelumnya diatas.

\section{Definisi Pelamar dan Pencari Kerja}

Pengertian pelamar dan pencari kerja atau pengguna adalah orang yang belum mendapatkan pekerjaan atau sudah memiliki pekerjaan dan berusaha mencari pekerjaan baru sesuai dengan minat, bidang pendidikan maupun bakat serta kemampuan yang dimiliki dengan cara mengumpulkan sebanyak-banyaknya informasi mengenai perusahaan yang diminati dengan meminta informasi dan bantuan kolega yang dimiliki.

\section{Aplikasi}

Terdapat beberapa teori yang dikemukakan oleh ahli mengenai pengertian aplikasi, di antaranya: menurut Pramana (2012) Aplikasi adalah satu unit perangkat lunak yang dibuat untuk melayani kebutuhan akan beberapa aktivitas seperti sistem perniagaan, game, pelayanan warga, periklanan, atau semua proses yang hampir dilakukan manusia.

Menurut Yuhefizar (2012) aplikasi merupakan program yang dikembangkan untuk memenuhi kebutuhan pengguna dalam menjalankan pekerjaan tertentu.

\section{Lowongan Kerja}

Menurut Wahyudi (2015), lowongan kerja adalah suatu informasi tentang suatu pekerjaan yang tersedia bagi para pencari kerja khususnya bagi orang yang tidak mempunyai pekerjaan atau sedang mencari pekerjaan yang disertai dengan syaratsyarat tertentu. Dengan adanya informasi lowongan kerja dapat mengurangi pengangguran.

\section{Hybrid Application}

Menurut Gok dan Khanna (2013, p2) Aplikasi Hybrid adalah kategori khusus dari aplikasi web yang mempeluas lingkungan aplikasi berbasis web melalui penggunaan platform API asli yang tersedia pada perangkat tertentu. Pola desain aplikasi hybrid yang sama berlaku untuk kedua lingkungan mobile dan desktop

\section{Single Page Application}

Menurut Scott (2016.p81), SPA adalah pendekatan pengembangan web di mana seluruh aplikasi bertempat di satu halaman. Dalam SPA, tidak terjadi halaman penuh yang refresh ketika aplikasi dijalankan.

Sebaliknya, logika presentasi dimuat di depan dan disajikan dari segi tampilan yang berganti dalam wilayah konten. Seringkali format data yang digunakan dalam komunikasi SPA adalah teks berformat JSON.

Menurut Nizamettin Gok dan Nithin Khanna (2013, p94) SPA adalah aplikasi web di mana seluruh pengalaman pengguna terkandung dalam satu halaman web. Arsitektur SPA memberdayakan aplikasi web mobile menjadi lebih seragam. Aplikasi ini terus-menerus menjalankan halaman yang sama dengan pandangan yang berbeda atau konten, tapi tanpa reload atau menavigasi pergi ke sumber lain. Hal ini dicapai dengan memisahkan data dari 
lapisan presentasi dan sangat bergantung pada JavaScript.

\section{Javascript}

Berdasarkan pendapat Stark (2012, p9) JavaScript adalah bahasa scripting yang dapat ditambahkan ke halaman HTML untuk membuatnya lebih interaktif dan nyaman bagi pengguna. JavaScript dapat berkomunikasi dengan web server untuk mengeksekusi perubahan basis data tanpa melakukan refresh halaman web saat ini.

\section{HTML}

Menurut Sidik dan Pohan (2013, p9), HTML (Hypertext Markup Language) adalah file teks murni yang dapat dibuat dengan editor teks sembarangan. Dokumen ini dikenal sebagai web page. Dokumen HTML merupakan dokumen yang disajikan dalam browser web server. Dokumen ini umumnya berisi informasi atau interface aplikasi didalam internet.

\section{CSS}

Stark (2012.p6) mendefinisikan CSS sebagai bahasa stylesheet yang digunakan untuk menentukan presentasi visual dari suatu dokumen HTML. CSS dapat digunakan pada elemen-elemen untuk seluruh halaman aplikasi. Menurut Saputra (2012, p27) CSS merupakan bahasa pemrograman web yang didesain khusus untuk mengendalikan dan membangun berbagai komponen dalam web sehingga tampilan web menjadi lebih rapi, terstruktur, dan seragam.

\section{AngularJS}

AngularJS adalah sebuah JavaScript framework untuk berkerja dengan data secara langsung di frontend. AngularJs adalah client-side framework, yang memungkinkan untuk membangun seluruh aplikasi yang berjalan di browser (Simon Holmes, 2016.p16, p241).

Ionic

Ionic merupakan salah satu kerangka kerja hybrid mobile (mobile hybrid frameworks) yang paling banyak digunakan. Ionic adalah open source, frontend SDK untuk mengembangkan hybrid mobile apps dengan HTML5. Ionic menggunakan AngularJS sebagai kerangka JavaScript-nya (Ravulavaru 2015.p1, p22).

\section{Android}

Menurut Lee (2011, p3), Android adalah suatu sistem operasi mobile yang didasarkan pada versi modifikasi dari Linux. Pada awalnya dikembangkan oleh sebuah startup dengan nama yang sama yaitu Android.Inc. Pada tahun 2005, sebagai bagian dari strategi untuk masuk ke dalam ruang mobile, Google membeli Android dan mengambil alih dalam pengembangannya. Google menginginkan Android untuk menjadi suatu sistem operasi yang terbuka dan bebas, maka keseluruhan kode Android dapat dirilis di bawah lisensi Apache open source, yang berarti bahwa setiap pengguna Android dapat dengan mudah mengunduh source code secara leluasa. Selain itu, vendor (produsen hardware) dapat menambahkan eksistensi Android yang mereka miliki agar dapat disesuaikan dengan produk lain. Model pengembangan yang sederhana membuat Android terlihat sangat menarik perhatian dan dengan demikian telah mengganggu kepentingan para vendor lain. Keuntungan utama dari mengadopsi Android adalah sistem operasi yang menawarkan pendekatan seragam dalam pengembangan aplikasi. Pengembang hanya perlu mengembangkan aplikasi Android dan aplikasi yang mereka buat harus dijalankan pada perangkat Android yang berbeda-beda, selama perangkat yang didukung menggunakan Android. Android memiliki sejumlah pembaharuan semenjak rilis aslinya. Pembaharuan ini dilakukan untuk memperbaiki bug dan menambah fitur-fitur yang baru.

\section{Android SDK}

Menurut Safaat H (2012), Android SDK adalah tools API (Application Programming Interface) yang diperlukan untuk memulai mengembangkan aplikasi pada platform Android menggunakan bahasa pemrograman Java.

\section{REST Web Service}

REST merupakan singkatan dari Representational State Transfer. REST adalah sebuah model arsitektur untuk 
website dan web service yang sudah populer belakangan ini. Beberapa kerangka kerja MV* mendukung REST. Di dalam layanan RESTful, API mendefinisikan tipe media yang menyajikan sumber daya dan hasil aplikasi. URL dan metode HTTP digunakan dalam API untuk mendefinisikan aturan proses untuk tipe media yang sudah ditentukan (Scott 2016.p172).

\section{PHP}

Menurut Tarr (2012, p1) PHP (Hypertext Preprocessor) adalah sebuah bahasa multifungsi yang tidak terbatas untuk menjalankan sebuah website sehingga dapat membuat halaman web yang dinamis.

\section{Lumen}

Dikutip dari situs https://laravelnews.com/lumen, Lumen adalah merek baru framework PHP dari Taylor Otwell yang dirancang untuk membangun secara cepat micro-services dan API. Ketika kecepatan adalah sebuah kebutuhan, Lumen harus menjadi pilihan yang pertama. Salah satu hal yang rapi tentang kerangka kerja ini adalah anda masih bisa menggunakan semua fitur yang anda sukai seperti laravel Eloquent, caching, queues, validation, routing, middleware, dan powerful laravel service container.

\section{Basis Data}

Menurut Fathansyah (2014 p2), Basis Data (Database) sendiri dapat idefinisikan dalam sejumlah sudut pandang seperti: himpunan kelompok data (arsip) yang saling berhubungan yang diorganisasi sedemikian rupa agar kelak dapat dimanfaatkan kembali dengan cepat dan mudah. Kumpulan file/tabel/arsip yang saling berhubungan yang disimpan dalam media penyimpanan elektronis.

\section{MySQL}

Menurut DuBois (2014, p1) MySQL adalah suatu jenis database server yang banyak digunakan untuk membangun aplikasi web yang mana SQL tersebut berisikan sebuah SQL server, klien program untuk mengakses server, alat administrasi, dan sebuah program interface untuk menulis program yang anda miliki.
Menurut Sidik (2012, p333), menyebutkan bahwa : "MySQL merupakan software database yang termasuk paling popular di lingkungan Linux, kepopuleran ini karena ditunjang karena performansi query dari database-nya yang saat itu bisa dikatakan paling cepat dan jarang bermasalah".

\section{Unified Modeling Language (UML)}

UML adalah suatu metode yang banyak digunakan dalam memvisualisasikan dan mendokumentasikan desain sistem perangkat lunak dengan menggunakan konsep desain berorientasi objek tetapi independen dari bahasa pemrograman spesifik dan dapat digunakan untuk menjelaskan proses bisnis dan kebutuhan secara keseluruhan (Shelly dan Rosenblatt, 2015). UML menyediakan seperangkat alat yang telah terstandarisasi untuk mendokumentasikan analisis dan desain sistem perangkat lunak, yang terdiri dari hal, hubungan dan diagram. Diagram UML dapat dijabarkan menjadi use case diagram, class diagram dan activity diagram.

\section{METODOLOGI PENELITIAN}

\section{Kerangka Penelitian}

Berikut adalah kerangka pikir yang digunakan pada pembuatan prototipe aplikasi YourDreamJS yaitu menggunakan tahap-tahap pengembangan sistem model waterfall, alat bantu desain sistem berorientasi obyek berupa usecase dan activity diagram, bahasa pemrograman html, bahasa pemrograman php, database mysql, dan lain-lain sepert terlihat pada Gambar 1 berikut ini: 


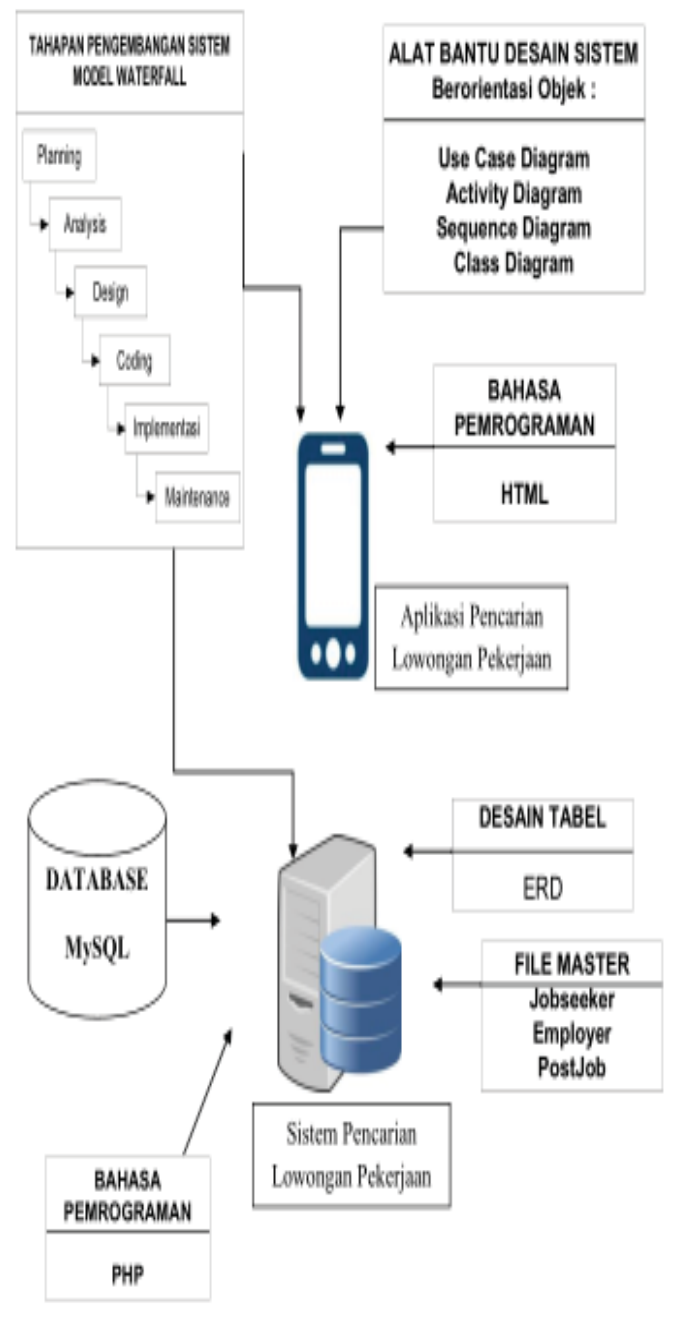

Gambar 1. Kerangka Penelitian

\section{Perumusan Objek Penelitian}

Perumusan Objek Penelitian atau Populasi dan Sampel, sampel yang digunakan untuk pengumpulan data adalah: warga pencari kerja dengan usia 20 sampai 25 tahun.

\section{Metode Pengumpulan Data}

Metode yang digunakan dalam penulisan artikel adalah: Studi pustaka, mengumpulkan berbagai referensi dan teori-teori yang berkaitan langsung dengan masalah pokok artikel. Kuesioner, menyebarkan kuesioner untuk mengetahui fitur-fitur yang diinginkan dan diharapkan oleh warga ketika mengakses aplikasi pencarian lowongan kerja.

\section{Metode Analisis Data}

Permasalahan, metode analisis yang digunakan untuk membuat aplikasi adalah UML Diagram meliputi Use Case Diagram, Activity Diagram dan Sequence Diagram dan juga menyusun diagram hubungan antar entitas (Entity Relationship Diagram).

\section{HASIL DAN PEMBAHASAN}

\section{Analisis Kebutuhan}

Keuntungan yang didapat dengan adanya aplikasi YourDreamJS adalah: Pengguna dapat mencari berbagai lowongan kerja yang diinginkan kapanpun dan di manapun dengan perangkat Android yang dimiliki. Pengguna dapat melamar pekerjaan yang cocok secara cepat dan mudah. Pengguna dapat mengubah informasi data diri dengan cepat dan mudah.

\section{Kebutuhan Fungsional}

Usability terdiri dari, Learnability: aplikasi ini akan mudah digunakan dan dipelajari oleh seluruh warga pencari kerja karena tidak memiliki tampilan yang rumit. Efficiency: aplikasi ini akan mempermudah warga dalam mencari lowongan kerja sesuai dengan kategori yang diinginkan. Errors: aplikasi ini akan menampilkan pesan gagal atau error jika terjadi kesalahan input oleh pengguna atau informasi yang dicari tidak ditemukan.

Reliability, aplikasi ini dapat diakses 24 jam secara online pada smartphone dengan Operating System Android 6.0 dan setelahnya. Aplikasi ini akan memberikan data lowongan kerja terbaru.

Flexibility \& Maintanability, untuk perkembangan aplikasi YourDreamJS, akan membutuhkan fleksibilitas untuk menyelaraskan data dan informasi yang disediakan dan mengembangkan fitur-fitur terbaru mengikuti perkembangan sistem yang sedang berjalan untuk memudahkan pengguna menggunakan aplikasi ini. Pemeliharaan sistem juga harus dapat dilakukan secara cepat agar perkembangan aplikasi dapat dilakukan secara maksimal.

Functionality, aplikasi YourDreamJS 
akan menjadi mesin pencari informasi lowongan pekerjaan yang diinginkan oleh pengguna. Pengguna dapat menggunakan berbagai kata kunci dan jenis lokasi dan perusahaan yang diminati untuk mencari informasi lowongan pekerjaan. Pengguna juga dapat mengganti informasi data diri melalui aplikasi ini.

\section{Analisis Pengguna}

Karakteristik pengguna yang akan menggunakan aplikasi ini adalah seluruh warga yang sedang mencari kerja. Pengguna tidak memerlukan keahlian khusus untuk menggunakan aplikasi ini. Pengguna hanya memerlukan smartphone dengan sistem operasi Android dan akun YourDreamJS untuk melamar kerja yang diingikan serta mengakses menu lainnya. Pengguna dapat mendaftar secara langsung untuk menjadi anggota YourDreamJS melalui aplikasi ini secara mudah dan cepat.

Pengertian pelamar dan pencari kerja atau pengguna adalah orang yang belum mendapatkan pekerjaan atau sudah memiliki pekerjaan dan berusaha mencari pekerjaan baru sesuai dengan minat, bidang pendidikan maupun bakat serta kemampuan yang dimiliki dengan cara mengumpulkan sebanyak-banyaknya informasi mengenai perusahaan yang diminati dengan meminta informasi dan bantuan kolega yang dimiliki.

\section{Analisis Hasil Kuesioner}

Kuesioner telah disebar secara online dengan jumlah responden sebanyak 35 orang yang terdiri dari pelajar atau pekerja, sebanyak 31 orang $(88.6 \%)$ dari jumlah responden merupakan pelajar dan 4 orang $(11,4 \%)$ merupakan pekerja. Dengan jumlah responden yang mayoritas pelajar, prototipe aplikasi ini diharapkan dapat digunakan untuk mencari lowongan pekerjaan setelah responden menyelesaikan dunia pendidikan.

Sebanyak 26 orang $(74,3 \%)$ dari jumlah responden masih menggunakan situs pencarian lowongan pekerjaan untuk mencari lowongan pekerjaan, 7 orang (20\%) sudah menggunakan aplikasi mobile yang telah tersedia saat ini dan 2 orang $(5,7 \%)$ mencari lowongan pekerjaan melalui media lain. Hasil ini juga memberikan tantangan untuk mencari cara untuk mensosialisasikan aplikasi mobile yang dibuat agar dapat digunakan secara maksimal dan memudahkan masyarakat dalam mencari lowongan pekerjaan.

Sebanyak 28 orang (80\%) dari jumlah responden merasa tertarik jika ada aplikasi pencarian lowongan pekerjaan berbasis mobile yang mudah dan cepat. 2 orang $(5,7 \%)$ tidak merasa tertarik dan 5 orang $(14,3 \%)$ merasa mungkin agak tertarik. Jadi warga masih membutuhkan aplikasi baru dalam mencari lowongan pekerjaan.

Pertanyaan yang diajukan adalah mengenai fitur-fitur yang responden harapkan ketika menggunakan aplikasi mobile pencarian lowongan pekerjaan. Responden dapat memilih lebih dari satu pilihan yang disediakan. Sebanyak 29 orang atau $82,9 \%$ memilih fitur pencarian secara lengkap dan sesuai dengan kata kunci sebagai fitur yang penting, kemudian diikuti dengan tampilan aplikasi yang simple yang dipilih oleh 21 orang $(60 \%)$. Sebanyak 18 orang $(51,4 \%)$ menginginkan aplikasi yang akan dibuat dapat langsung menyediakan fitur melamar pekerjaan.

Pertanyaan yang diajukan adalah informasi yang diperlukan oleh responden ketika ingin mencari lowongan pekerjaan. Responden dapat memilih pilihan yang ada lebih dari satu, sebanyak 28 orang $(80 \%)$ memilih pilihan lokasi perusahaan yang diinginkan harus tersedia. Diikuti dengan pilihan gaji yang diinginkan (24 orang atau 68,6\%). Setelah itu jenis industri perusahaan yang diinginkan ketika responden ingin mencari informasi lowongan pekerjaan.

\section{Analisis Sistem Berjalan}

Untuk mendapatkan informasi lowongan kerja, selama ini warga masih menggunakan media cetak seperti surat kabar, mengikuti berbagai job fair dan event-event seperti campus hiring dan melalui rekomendasi dari saudara maupun teman. Cara ini membutuhkan biaya dan waktu yang tidak sedikit apabila harus membeli banyak surat kabar dan memilih 
informasi lowongan kerja yang sesuai dengan keahlian yang dimiliki. Selain itu, media seperti internet juga dapat digunakan untuk melihat berbagai website penyedia informasi lowongan pekerjaan yang sudah ada saat ini. Namun, apabila warga mengakses website melalui smartphone, akan muncul kendala seperti tampilan yang tidak sesuai di layar smartphone serta waktu akses yang lama untuk menampilkan semua konten yang ada di website tersebut. Adanya prototipe aplikasi YourDreamJS kiranya akan membantu warga dalam mencari informasi lowongan kerja melalui smartphone dengan tampilan yang tidak rumit dan waktu akses yang cepat.

Warga membeli surat kabar atau koran untuk melihat informasi lowongan pekerjaan. Apabila melihat lowongan pekerjaan yang cocok dan sesuai, maka warga dapat mengirimkan lamaran dan data diri ke perusahaan terkait melalui pos. Apabila pihak perusahaan tertarik atau berminat, maka warga akan datang ke perusahaan untuk melakukan wawancara.

\section{Use Case Diagram}

Aktor terdiri dari pengguna dan anggota. Pengguna dapat mencari lowongan kerja yang diinginkan, namun tidak dapat melamar kerja. Pengguna harus menjadi anggota terlebih dahulu sebelum melamar kerja dan memilih menu lainnya. Pilihan register tersedia apabila pengguna tertarik menjadi anggota dari YourDreamJS. Anggota dapat mencari data lowongan kerja (Search Job), melamar kerja (Apply Job) dan juga melihat riwayat lowongan kerja yang pernah dilamar ataupun disimpan.

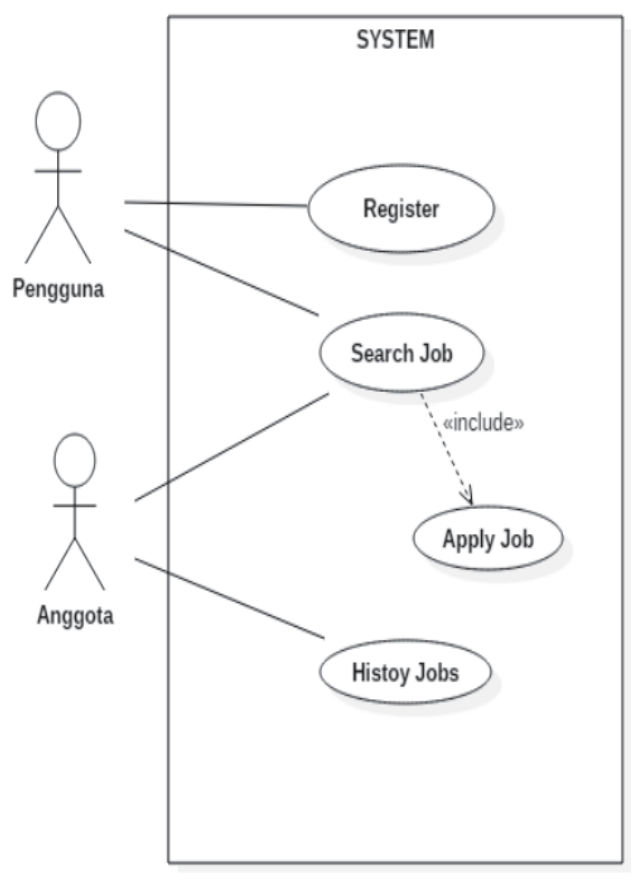

Gambar 2. Use Case Diagram

\section{Activity Diagram}

Pengguna dapat memilih pilihan Register untuk mendaftar menjadi anggota YourDreamJS. Pengguna diwajibkan untuk mengisi data diri pada form yang disediakan. Setelah selesai mengisi seluruh data, maka sistem akan melakukan pengecekan akun sudah ada atau belum. Jika data sudah ada, maka pengguna harus mengisi kembali data dengan data yang berbeda. Jika data belum ada, maka pengguna akan mengisi data yang selanjutnya dan melakukan konfirmasi. Setelah konfirmasi, maka sistem akan menyimpan data ke basis data dan akan membuat kode aktivasi kemudian mengirimkan kode tersebut melalui email. Kemudian pengguna akan mengisi kode aktivasi. Jika sukses, akan terdapat pemberitahuan bahwa akun berhasil diaktivasi dan halaman akan berganti menuju halaman Login. Jika gagal, maka pengguna harus mengisi ulang kode aktivasi.

Pengguna dapat mengisi seluruh kategori yang disediakan lalu menekan tombol Search untuk mencari data lowongan kerja yang sesuai. Kemudian 
sistem akan mencari data yang sesuai. Jika data tidak ada, maka pengguna dapat mengubah kategori yang ada. Jika data ditemukan, seluruh data akan ditampilkan. Pengguna dapat memilih lowongan kerja yang tersedia, kemudian sistem akan memberikan rincian dari lowongan kerja yang dipilih.

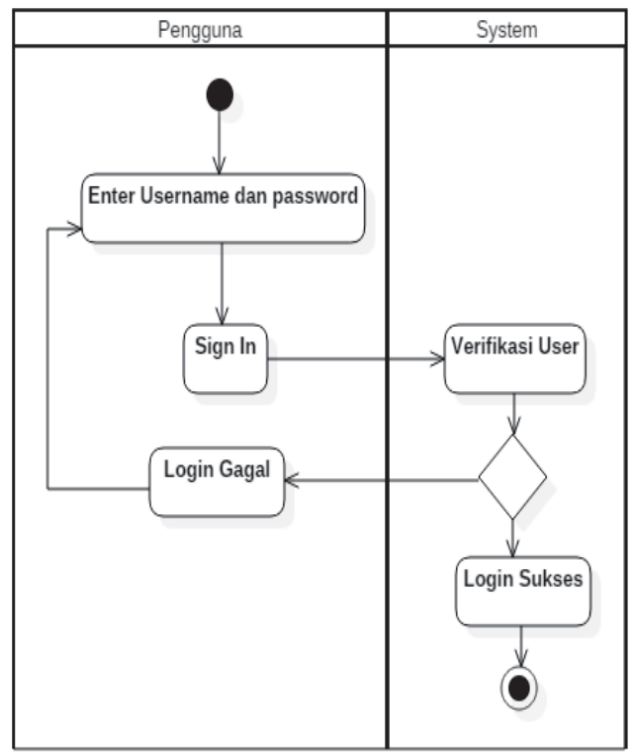

Gambar 3. Activity Diagram Login

Pengguna dapat melakukan login dengan mengisi username atau email dan password. Jika data yang dimasukkan terdapat di basis data, maka login berhasil dan halaman akan berganti dengan menu untuk anggota. Jika login gagal, maka akan pemberitahuan pesan gagal dan anggota dapat memasukkan data akun kembali.

\section{Perancangan Tampilan}

Ketentuan untuk seluruh gambar, kotak yang bergaris tebal merupakan tombol (button). Pengguna dapat mengakses halaman di gambar bawah ketika memilih pilihan Login pada menu dibawah layar. Pengguna akan mengisi kolom Username/Email Address dan Password sesuai dengan akun yang dimiliki, kemudian menekan tombol SIGN IN. Jika memilih Register, maka halaman akan menuju halaman pendaftaran. Pilihan Forgot password akan menuju ke halaman lupa password.

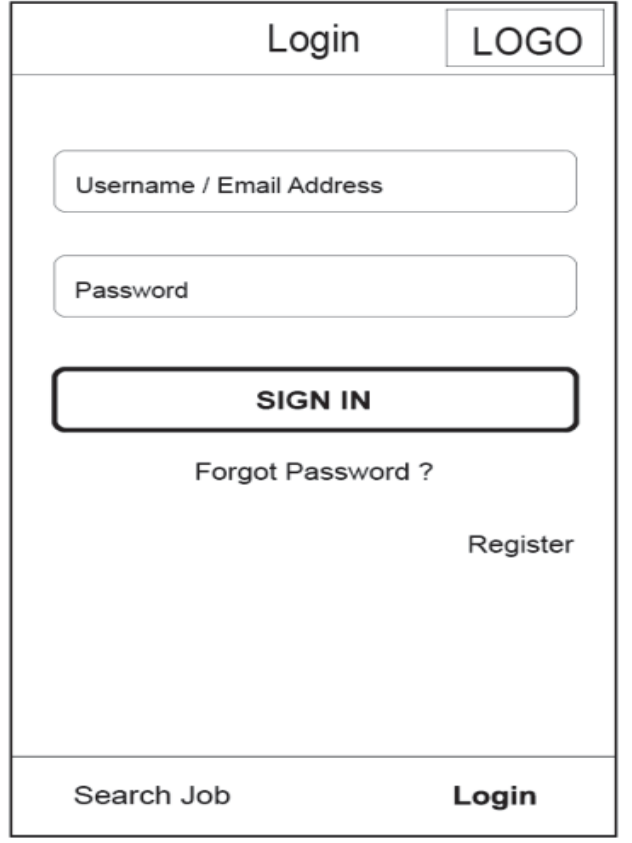

Gambar 4. Halaman Login

\section{Hasil Tampilan}

Salah satu contoh hasil tampilan yaitu Halaman Detail Job - Anggota adalah sebagai berikut:
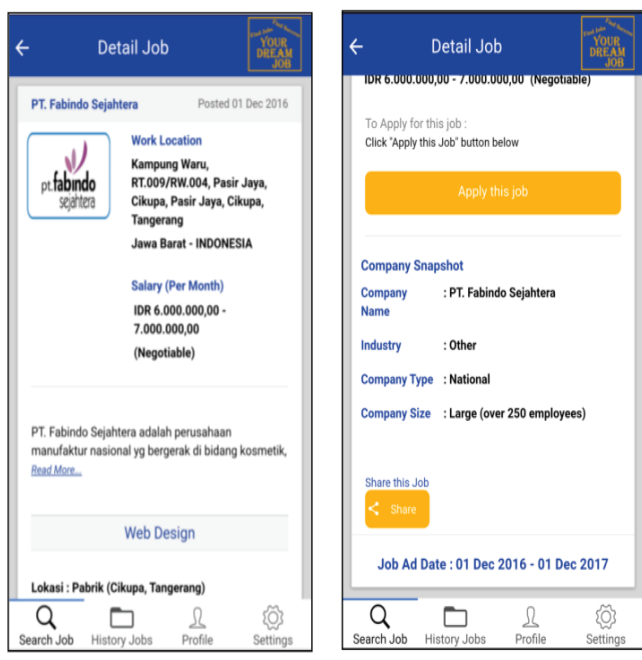

Gambar 5. Halaman Detail Job - Anggota

\section{KESIMPULAN DAN SARAN}

\section{Kesimpulan}

Dari keseluruhan yang sudah dilakukan oleh peneliti untuk prototipe aplikasi YourDreamJS, maka didapat kesimpulan sebagai berikut: 
3. Prototipe aplikasi YourDreamJS memudahkan warga dalam mencari berbagai informasi lowongan kerja, secara mudah dan cepat.

4. Prototipe aplikasi YourDreamJS sudah memberikan output yang sesuai dengan yang diinginkan. Berdasarkan hasil kuesioner setelah implementasi, dapat disimpulkan bahwa prototipe aplikasi YourDreamJS dapat digunakan dengan mudah oleh sebagian besar responden $(91,7 \%)$ dalam mencari informasi lowongan kerja yang diinginkan. Sebagian besar responden (75\%) juga tertarik untuk menggunakan prototipe aplikasi YourDreamJS.

\section{Saran}

Adapun saran untuk penulisan selanjutnya, adalah sebagai berikut:

1. agar dapat digunakan secara maksimal oleh seluruh pencari kerja antara lain: penambahan fitur untuk mendeteksi lokasi dan mencari lokasi perusahaan terdekat yang membuka lowongan kerja. Penambahan fitur push notification (optional) untuk setiap lowongan kerja yang baru.

2. Perbaikan bug yang ada di prototipe aplikasi YourDreamJS.

3. Penambahan fitur lainnya yang dapat menunjang dalam pencarian informasi lowongan kerja.

4. Untuk memperluas jangkauan pengguna peneliti harapkan dapat dibuat untuk aplikasi iOS-nya juga.

\section{DAFTAR PUSTAKA}

Agarwal, B. B., S. P. Tayal, M. Gupta. (2010), SOFTWARE ENGINEERING \& TESTING, Jones and Barlett Publisher, Sudbury.

Bogle, Salathiel dan Sankaranarayanan, Suresh, (2012), JOB SEARCH SYSTEM IN ANDROID ENVIRONMENT - APPLICATION OF INTELLIGENT AGENTS, International Journal of Information Sciences and Techniques (IJIST) Vol.2, No.3, May 2012, Kingston.
DuBois, Paul. (2014), MySQL (5th Edition), Addison-Wesley, USA.

Fathansyah. (2012), Basis Data, Informatika Bandung, Bandung.

Gok, Nizamettin and Nitin Khanna. (2013), Building Hybrid Android Apps with Java and JavaScript, O'Reilly Media, Inc, USA.

Green, Brad and Shyam Seshadri. (2013), AngularJS, O’Reilly Media, Inc, USA.

Hariyanto, Bambang. (2011), Esensi-esensi Bahasa Pemerograman Java, Informatika, Bandung.

Hendrayudi. (2009), Pengertian Aplikasi, Andi, Yogyakarta.

Holmes, Simon. (2016), Getting MEAN with Mongo, Express, Angular, and Node, Manning Publications Co, USA.

Maanari, J.I. (2013), Perancangan Basis Data Perusahaan Distribusi dengan Menggunakan Oracle (Jurnal),UNSRAT, Manado.

Meng Lee, W. (2011), Begining Android Application Development, Wiley Publishing. Inc, Indianapolis.

Pramana, Hengky W. (2012), Aplikasi Inventory Berbasis Access 2003, PT. Elex Media Komputindo, Jakarta.

Raharjo,Budi (2015), Belajar Otodidak MySQL, Informatika, Bandung.

Ravulavaru, Arvind. (2015), Learning Ionic- Build real-time and hybrid mobile application with Ionic, Packt Publishing Ltd, Burningham.

Safaat, Nazruddin H. (2012), Pemrograman Aplikasi Mobile Smartphone dan Tablet PC Berbasis Android. Informatika. Bandung.

Saputra, Agus. (2012), Webtips: PHP HTML5 dan CSS3, Jasakom, Jakarta.

Schwalbe, Kathy. (2014), Information Technology Project Management (7th edition), Cengage Learning, USA. 
Scoot, Emmit A. (2016), SPA Design and Architecture, Manning Publications Co, USA.

Shelly, Gary B. danVermaat, Misty E. (2012), Menjelajah Dunia Komputer -Hidup dalam Era Digital (Edisi 15), Salemba Infotek, Jakarta Selatan.

Shelly, Gary B. dan Harry J. Rosenblatt. (2015), Analysis and Design for Systems (9 th Edition), Cengage Learning, USA.

Shelly, Gary B. dan Harry J. Rosenblatt. (2011), Systems Analysis and Design Ninth Edition, Cengage Learning, USA.

Sidik, Betha. (2012), Pemrograman Web dengan PHP, Informatika, Bandung.

Sidik, Betha dan Husni I.Pohan. (2013), Pemrograman Web dengan HTML, Informatika, Bandung.

Stark, Jonathan with Brian Jepson. (2012), Building Android Apps with HTML, CSS, and JavaScript, O'Reilly Media, Inc, USA.

Tarr, Andrea. (2012), PHP and MySQL, John Wiley \& Sons, Inc, USA.

Wahyudi, Tri dan Rachmadi, Muhammad.(2015), Sistem Informasi Lowongan Pekerjaan Berbasis Android (Jurnal), dari http://eprints.mdp.ac.id/1627/,

Diakses 14 November 2016, STMIK GI MDP, Palembang.

Yuhefizar. (2012), Cara Mudah Membangun Website Interaktif Menggunakan CMS Joomla Edisi Revisi, PT. Elex Media Komputindo, Jakarta. 